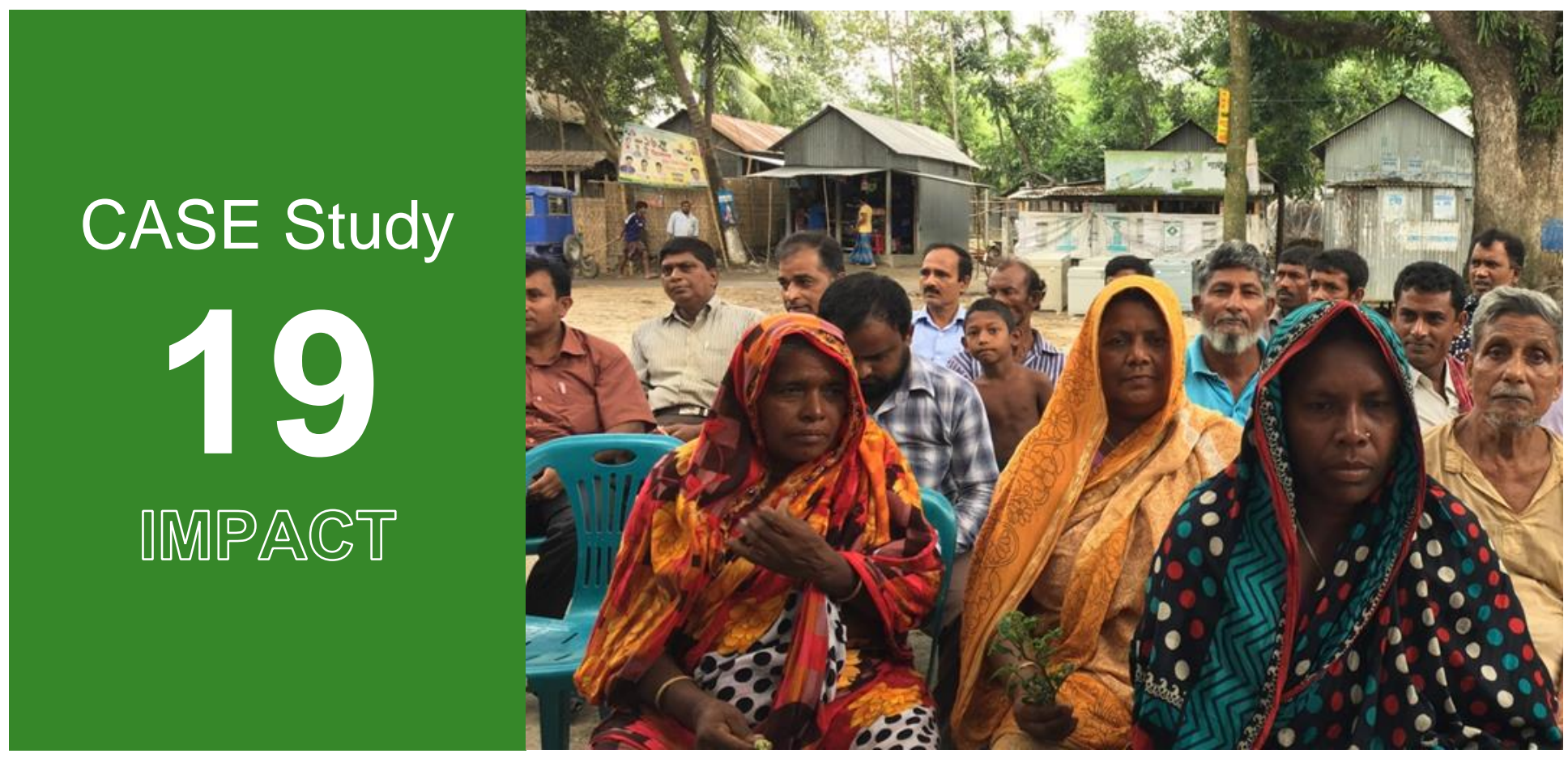

\title{
Plant clinics in Bangladesh: are farmers losing less and feeding more?
}

\section{Summary}

Agriculture accounts for around one-third of Bangladesh's gross domestic product and more than $30 \%$ of money earned from exporting to other countries. Nearly two-thirds of the country's population works in agriculture, and around $80 \%$ depend on it for their livelihoods. The country's major crop is rice, planted on $75 \%$ of farmland, with the remainder including high-value vegetables, fruits and spices. Pests destroy between $10 \%$ and $25 \%$ of harvests, despite the estimated 49,000 tonnes of pesticides used by farmers every year.

The Plantwise programme, led by $\mathrm{CABI}$, aims to contribute to increased food security, alleviated poverty and improved livelihoods by enabling men and women farmers around the world to lose less, produce more and improve the quality of their crops. In Bangladesh, a 2017 study has revealed that farmers who regularly attend plant clinics are more likely than non-users to be able to identify and manage crop problems, as well as increase crop yields and profitability. With increased knowledge of improved farm practices, plant clinic users are also having to rely less on chemical fertilisers to manage pests and diseases. 


\section{Key highlights}

- 4,046 queries were recorded across 30 plant clinics between January 2015 and April 2017.

- $100 \%$ of plant clinic users felt their ability to quickly identify crop problems had increased, compared to $16 \%$ of non-users.

- Plant clinic users were 4.6 times more likely to indicate that their farm management knowledge had increased compared to non-users.

- $93 \%$ of plant clinic users fully implemented the advice they received from plant doctors; $100 \%$ of these users stated that the advice worked well in tackling crop health problems.

- $80 \%$ of plant clinic users stated that the frequency with which they used pesticide sprays had decreased.

- $100 \%$ of plant clinic users experienced yield increases, with $84 \%$ stating that the plant clinic had played a major role.

- $73 \%$ of plant clinic users said their overall profitability had increased as a result of attending the clinic.

\section{Context}

Major crops and commodities important for food security, income generation and world trade suffer from frequent and severe production constraints due to poor management of agroecosystems, often the result of limited knowledge on agricultural best practice, including rational use of inputs such as pesticides. Moreover, production intensification and climate change - along with globalisation of trade and travel accelerate the spread of invasive plant pests and diseases, and increase their impact on crops.

Although there continues to be significant losses of food to plant pests and diseases, there is a poor and irregular flow of information about the threats that farmers face. Nutrient deficiencies are difficult to diagnose and pest problems can flare up unpredictably, yet often, there is no mechanism for responding quickly or providing the technical support necessary to confirm causes and suggest effective, accessible, and pragmatic solutions. The poorer the farmer, the greater the impact of making the wrong decision or failing to get advice in time.

Working closely with national agricultural advisory services, Plantwise establishes and supports sustainable networks of local plant clinics, run by trained plant doctors, where farmers can receive practical plant health advice. Farmers visit the clinic with samples of their crops, and plant doctors help diagnose the problem and make science-based recommendations on ways to manage it.

Plant clinics are reinforced by the Plantwise Knowledge Bank, which offers plant health information, including diagnostic resources, pest management advice and frontline pest data for effective global vigilance. Together, these two unique resources are part of the Plantwise approach to strengthen national plant health systems from within. The stronger the national plant health system, the better equipped the country will be to help farmers provide a safe and sustainable food supply and improve their livelihoods.

In Bangladesh, Plantwise was initially implemented by CABI in partnership with NGOs, but more recently has been implementing a new approach which is helping to strengthen national plant health systems from within by bringing the many different people who play a role in delivering knowledge to farmers together into a single approach. In 2015, new collaboration with the government was launched through a memorandum of understanding between the Ministry of Agriculture (MoA), the Economic Relations Division of the Ministry of Finance and CABI. The MoA is represented by the Plant Protection Wing 
(PPW) within the Department of Agricultural Extension (DAE), which currently leads in-country activities including establishment and operation of plant clinics and engagement with plant health system stakeholders. The aim of the collaboration was to build local capacity in plant pest and disease management to enable frontline extension workers to make accurate diagnoses and provide practical recommendations to farmers, and provide farmers greater opportunities to discuss their problems with reliable plant doctors.

The new programme initially began by establishing ten plant clinics in five districts and has gradually scaled up to 30 plant clinics in ten districts (Dhaka, Gazipur, Gopalganj, Khulna, Manikganj, Mymensingh, Narayanganj, Rajshahi, Sherpur and Tangail). Plant doctors are generally extension officers with knowledge of agronomy and crop protection, who are taught to use their knowledge in improved approaches to field diagnosis and in giving pragmatic advice. They are able to access information on pests and diseases from the Plantwise Knowledge Bank, while a mobile-based application (Plantwise Factsheet Library app ${ }^{1}$ ) provides access to 31 factsheets and 28 pest management guides in local languages on common pests and diseases that affect priority crops. A field diagnostic guide was also translated into Bangla and printed and shared with plant doctors. Data on crops brought to clinics - including observed symptoms, diagnoses and recommendations made - are recorded and then uploaded to the Plantwise Online Management System (POMS), which, as well as storing useful monitoring information about Plantwise activities, also provides valuable analyses of plant clinic data.

\section{What we did}

In 2017, primary and secondary data was collected to assess the impact of Plantwise on farmers' knowledge, attitude and practices (KAP) towards solving croprelated problems and then determine the impact KAP changes had on their yield and income. As well as reviewing secondary data from POMS, the research team also interviewed farmers from four Upazila (subdistricts) where plant clinics were located (see Figure 1). Initially a focus group discussion (FGD) was held in two of the Upazila (Kalikoire in Gazipur district, and Saturia in Manikgonj district) with a total of 55 farmers (35 men and 20 women, and a mixture of clinic users and nonusers). Approximately $30 \%$ of the farmers who had taken part in the FGDs then participated in one-on-one interviews, which were also carried out with farmers in an additional two Upazila (Dhamrai and Savar in

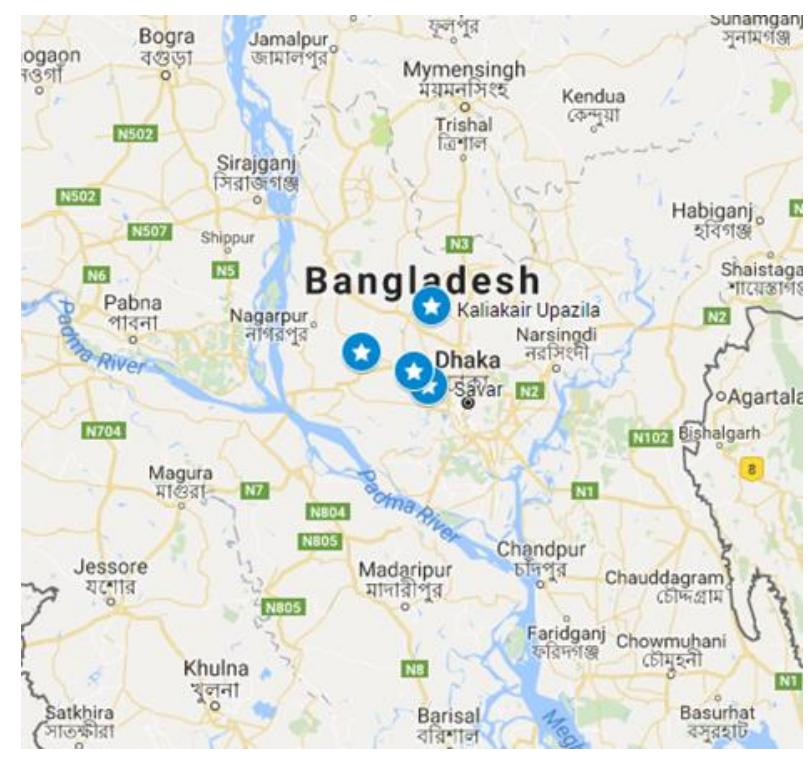

Figure 1: Survey sites Dhaka district). In each Upazila, plant doctors identified participating farmers who used plant clinics most often and then selected non-users from the same villages by putting out a general call for volunteers. They aimed to have a balance of men and women.

During the one-on-one interviews, a questionnaire was used to gather in-depth information from 30 clinic users and 30 non-users. In addition to collecting information about the characteristics of each farmer and their household, and where they sourced their information, the questionnaire also analysed KAP changes towards solving crop-related problems over a three-year period (2015-2017). If a farmer was a plant clinic user, they were also asked about the pest management information they had received.

$1 \mathrm{https}: / /$ play.google.com/store/apps/details?id=org.cabi. pfff\&hl=en 


\section{What impact was achieved?}

\section{POMS data}

POMS data from Plantwise Bangladesh revealed that 4,046 queries were recorded across the 30 plant clinics between January 2015 and April 2017 (Table 1). Most of the queries plant doctors were presented with affected rice and brinjal crops - priority crops in Bangladesh - and coconut, which is commonly grown in the surveyed regions.

Data also reveal a gradual increase in queries (Figure 2). Data inputted into POMS is initially collected on paper and then digitised, so the drop off in 2017 is likely caused by a delay in digitising the data. This is one reason for a move to collect the data electronically. So far, ten tablets have been issued to plant doctors that cover 16 clinics; the aim is for all plant clinics to have access to a tablet by the end of 2018 . In other countries, the introduction of tablets has also led to an increase in clinic records.

Table 1: POMS data (January 2015 to April 2017)

\begin{tabular}{|l|l|l|l|l|}
\hline & Men & Women & Unrecorded & Total \\
\hline Number of queries & 3,368 & 220 & 458 & 4,046 \\
\hline Top crops & & & & \\
\hline Rice & 379 & 3 & 12 & 394 \\
\hline Brinjal & 254 & 10 & 45 & 309 \\
\hline Mango & 235 & 15 & 46 & 296 \\
\hline Coconut & 182 & 19 & 38 & 239 \\
\hline Top pests and diseases & & & & \\
\hline Rice stem borer & 10 & 0 & 1 & 11 \\
\hline Cocount nutrient deficiency & 5 & 1 & 1 & 7 \\
\hline Rice sheath blight & 3 & 0 & 0 & 3 \\
\hline
\end{tabular}

\section{Queries over time}

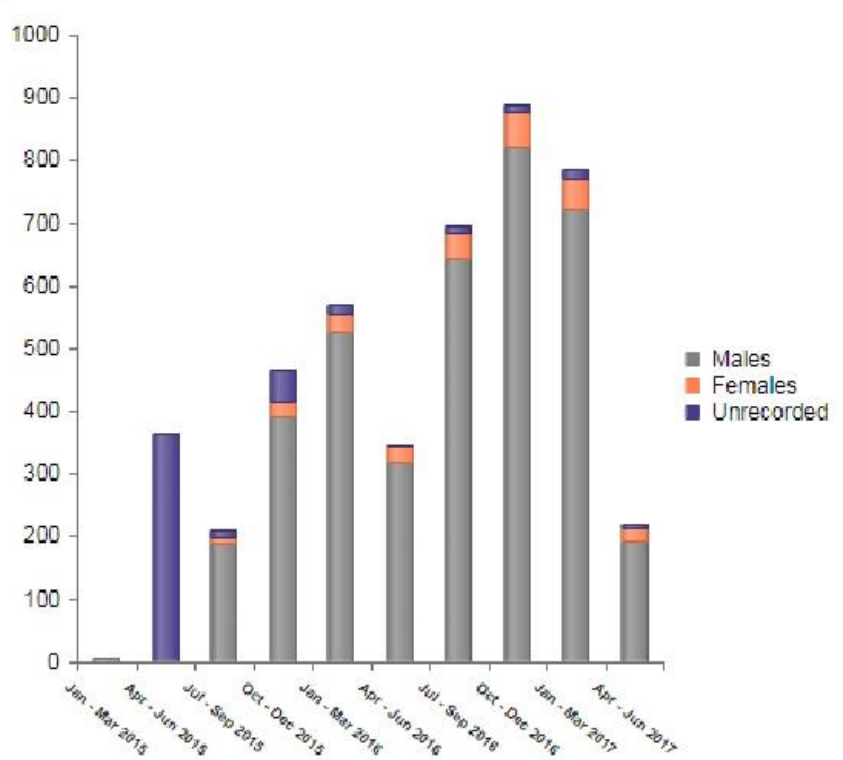

\section{Top crops}

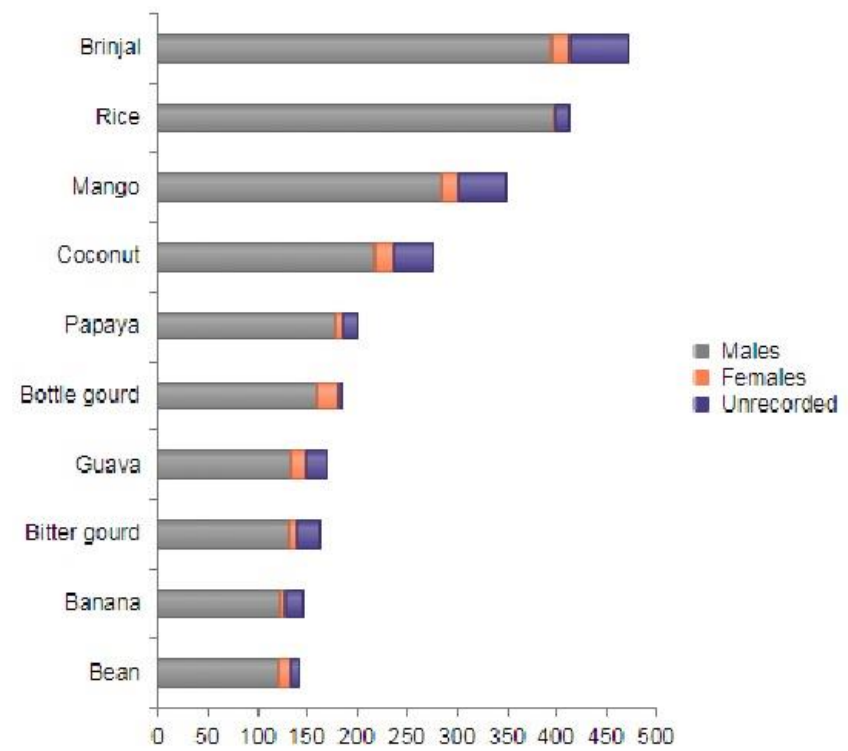

Figure 2: Numbers of queries and the top crops (January 2015 to April 2017) 
The POMS data also reveal low participation levels of women at plant clinics. A 2015 survey had already identified this trend so, in 2016, a separate survey of 340 women farmers from five districts (Gopalgaunj, Jhenaidah, Manikgaunj, Narayangaunj and Rajsahi) aimed to identify gendered differences in access to clinics and ask local women about clinic site locations and timings.

The 2016 survey found that many of the women were not aware of the plant clinics, but most expressed an interest in attending one. Holding clinics in the afternoon, between 2-5 pm, was the preferred option, with $67 \%$ of women stating they would attend an afternoon clinic. The majority of women (40\%) stated that their preferred location for a plant clinic would be a school, followed by market places (30\%), farmers' houses (20\%), and trading centres (10\%). The availability of female plant doctors would also encourage more women (58\%) to attend. As a result of the survey, the PPW has moved the timings of ten clinics to between 2-5 pm and their locations to markets or schools.

\section{Farmer interviews}

Demographics: Frequent clinic users were selected to be surveyed - with a bias towards female users to ensure their views were heard. The majority were also long-term users; $50 \%$ had been attending clinics since $2015,37 \%$ since 2016 , and $13 \%$ since 2017 . Amongst the users, $56 \%$ of surveyed farmers had visited a clinic more than 10 times in a 12-month period and, on average, farmers visited 12 times in a year. This contrasts with POMS data that showed, for example, that in 2016 , only $4 \%$ of clinic clients brought eight or more queries to the clinics while $84 \%$ brought only one to two queries. On average, farmers brought 1.4 queries. It may be that at some clinic sessions, records are not filled for all of the attending farmers.

A comparison of plant clinic user and non-user farmer groups (Table 2), revealed some interesting differences. Of the 60 farmers who completed the questionnaire, clinic users were, on average, slightly younger than the non-users questioned, although the difference was small (Table 2). Compared to nonusers, more farmers in the user group were women, reflecting the purposive sampling of women. Clinic users also tended to have higher levels of education, with $37 \%$ of non-users having no or primary education only, compared to $26 \%$ of users. The survey also revealed that plant clinic users were more likely to have been farming for a longer period of time that non-users, yet non-users farmed more land than users, and were also less likely to have an alternative income (including construction, tailoring, small agribusinesses).

Table 2: Characteristics of respondents and the households they represented

\begin{tabular}{|l|l|l|}
\hline \multicolumn{3}{|l|}{ Clinic users } \\
\hline Respondent characteristics & 30 & 30 \\
\hline Number $(\mathrm{n})$ & $60 \%(18)$ & $77 \%(23)$ \\
\hline$\%$ men & $40 \%(12)$ & $23 \%(7)$ \\
\hline$\%$ women & $57 \%(17)$ & $66 \%(19)$ \\
\hline$\%$ household head & 44 & 48 \\
\hline Average age & 44 & $10 \%(3)$ \\
\hline Education & $13 \%(4)$ & $27 \%(8)$ \\
\hline$\%$ no education & $13 \%(4)$ & $53 \%(16)$ \\
\hline$\%$ primary school & $57 \%(17)$ & $10 \%(3)$ \\
\hline$\%$ high school & $17 \%(5)$ & \\
\hline$\%$ university/technical college & \multicolumn{2}{|l|}{} \\
\hline Farming experience & $70 \%(21)$ & $64 \%(19)$ \\
\hline$\%>10$ years & $27 \%(8)$ & $23 \%(7)$ \\
\hline$\% 4-9$ years & $3 \%(1)$ & $13 \%(3)$ \\
\hline$\%<3$ years &
\end{tabular}




\begin{tabular}{|c|c|c|}
\hline & Clinic users & Non-users \\
\hline \multicolumn{3}{|l|}{ Household characteristics } \\
\hline Average household size & 4 & 3.7 \\
\hline \multicolumn{3}{|l|}{ Average land farmed } \\
\hline Legally owned (acres) & 47.92 & 63.63 \\
\hline Tenant farmers (acres) & 8.23 & 16.7 \\
\hline Rented (acres) & 4.75 & 13.2 \\
\hline$\%$ with alternative income & $56.6 \%$ & $46.6 \%$ \\
\hline
\end{tabular}

${ }^{\star} 83 \%$ of all men surveyed were household heads. While $16 \%$ of women who used clinics were household heads, no female non-users were household heads.

Source of plant health information: The study found that the main sources of information on plant health for plant clinic users were plant clinics (87\%) and government extension workers (77\%) (Figure 3). It is important to note that, while plant doctors are also government extension staff, clinic users have distinguished between visits to clinics and other occasions when they interacted with extension staff. While government extension workers were also an important source of information for non-users (57\%), non-users were much more likely to consult an agro-dealer (43\%) than plant clinic users (17\%). This may reflect a preference by farmers to consult a more trusted source of information, such as an agrodealer, when possible.

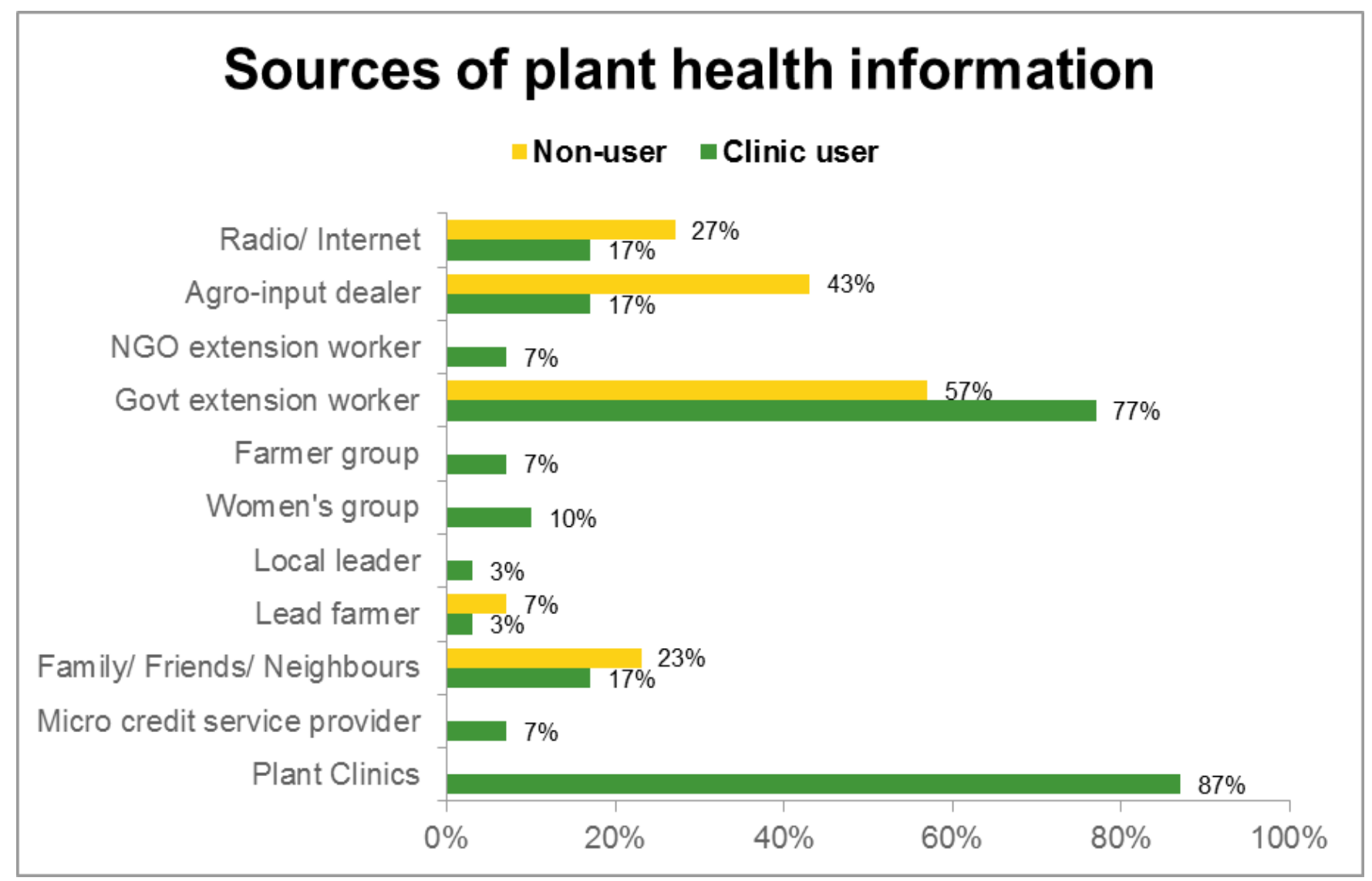

Figure 3: Preferred source of plant health information

The 30 farmers who frequently visited plant clinics were asked about the advice they had received from plant doctors. Most received advice about rice (56\%), but brinjal, bitter gourd, mango and coconut were also key crops. The study revealed that $93 \%$ of farmers had fully implemented the advice they received, 
while $7 \%$ partially implemented it (Figure 4), indicating that farmers trust plant doctors' recommendations. The survey team also found that $100 \%$ of farmers who fully implemented the advice given by the plant doctor found that it had worked well in tackling their crop health problems.

Plant clinic users stated that the plant clinics provided an array of technological solutions including cultural $^{2}$ (e.g. weeding to reduce harborage, and crop rotation), biological (e.g. use of pheromone and light traps, as well as neem) and chemical methods (insecticides etc.). Plant doctors are trained to ensure that they recommend rational use of chemical pesticides (avoiding red-list chemicals that are not nationally and internationally permissable, ecologically safe and environmentally sustainable; and making sure farmers do not spray more than needed, etc.) and encourage cultural practices to ensure that they offer sustainable plant health management advice. The survey revealed that most farmers (25 of the 30 surveyed) had received a chemical-based recommendation (insecticide, fungicide, etc.), followed by cultural and biological control options (Figure 5).

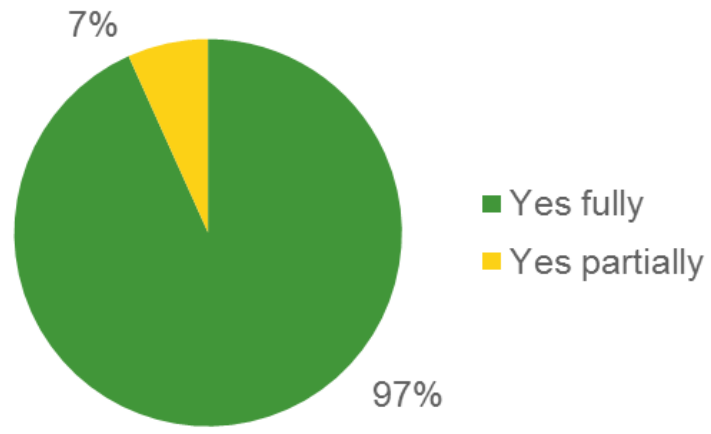

Figure 4: Users use of advice

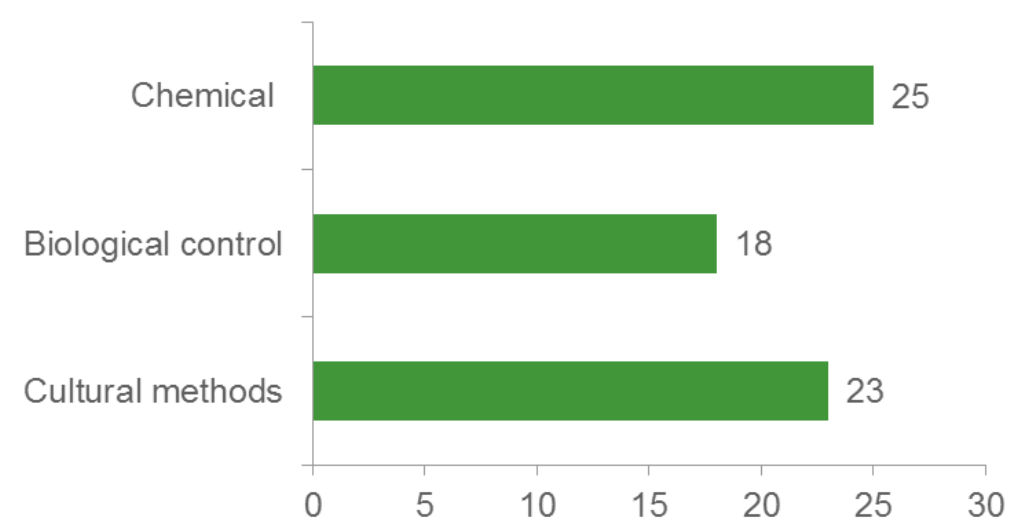

Figure 5: Plant doctors' advice to farmers

The survey also asked farmers to identify new agricultural technologies and practices that they adopted after hearing about them at plant clinics. The technology adopted by most farmers (56\%) was pheromone traps, which are used to attract pests either as an early warning measure, or to manage pests. While widely available in Bangladesh, the traps are not commonly used because farmers often have limited knowledge about them. Other technologies and practices adopted by clinic users include light traps (25\%), quality seed (14\%), water management (10\%) and balanced nutrient use (5\%).

Impact on crop yield and income: While both plant clinic users and non-users had seen their yields increase over a three-year period (2015-2017), 100\% of plant clinic users experienced an increase compared to $<67 \%$ of non-users (Figure 6 ). Of the 30 farmers who attended plant clinics, $84 \%$ felt that the plant clinic had played a major role in the yield increase (Figure 7). Increased income was indicated by $96 \%$ of clinic users and $28 \%$ of these users attributed it to engagement with clinics. This compares to $76 \%$ of non-users who indicated increased income, with most attributing the increase to farm prices.

\footnotetext{
${ }^{2}$ Cultural controls are practices aimed at altering conditions, or pest behaviours or pest populations.
} 




Figure 6: Proportion of plant clinic users and non-users indicating type of yield change observed in the preceding three years

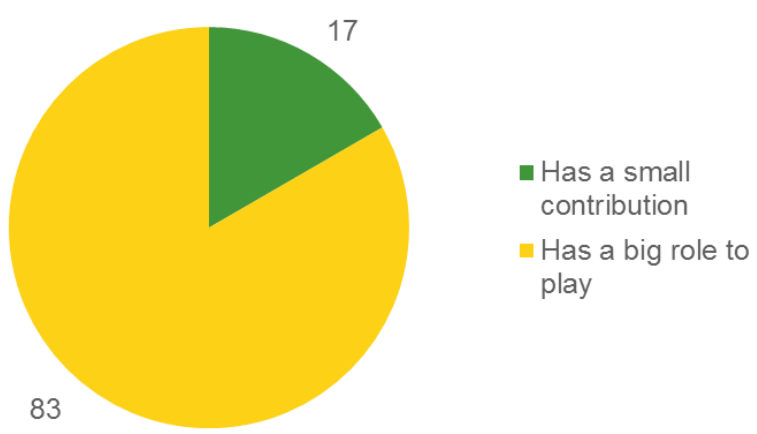

Figure 7: Role of plant clinic in yield increase

KAP changes: The survey revealed that plant clinic users significantly increased their ability to identify and address crop problems. More clinic users (97\%) than non-users (57\%) said they had increased their farming knowledge in the last three years (Figure 8). Of the clinic users who felt their knowledge had increased, $30 \%$ stated that they had more knowledge related to pests and diseases, and $30 \%$ mentioned knowing more about new technologies. For non-users who noted an increase, $65 \%$ referred to new knowledge on technologies such as seed varieties, while only $6 \%$ mentioned new knowledge on pests and diseases.

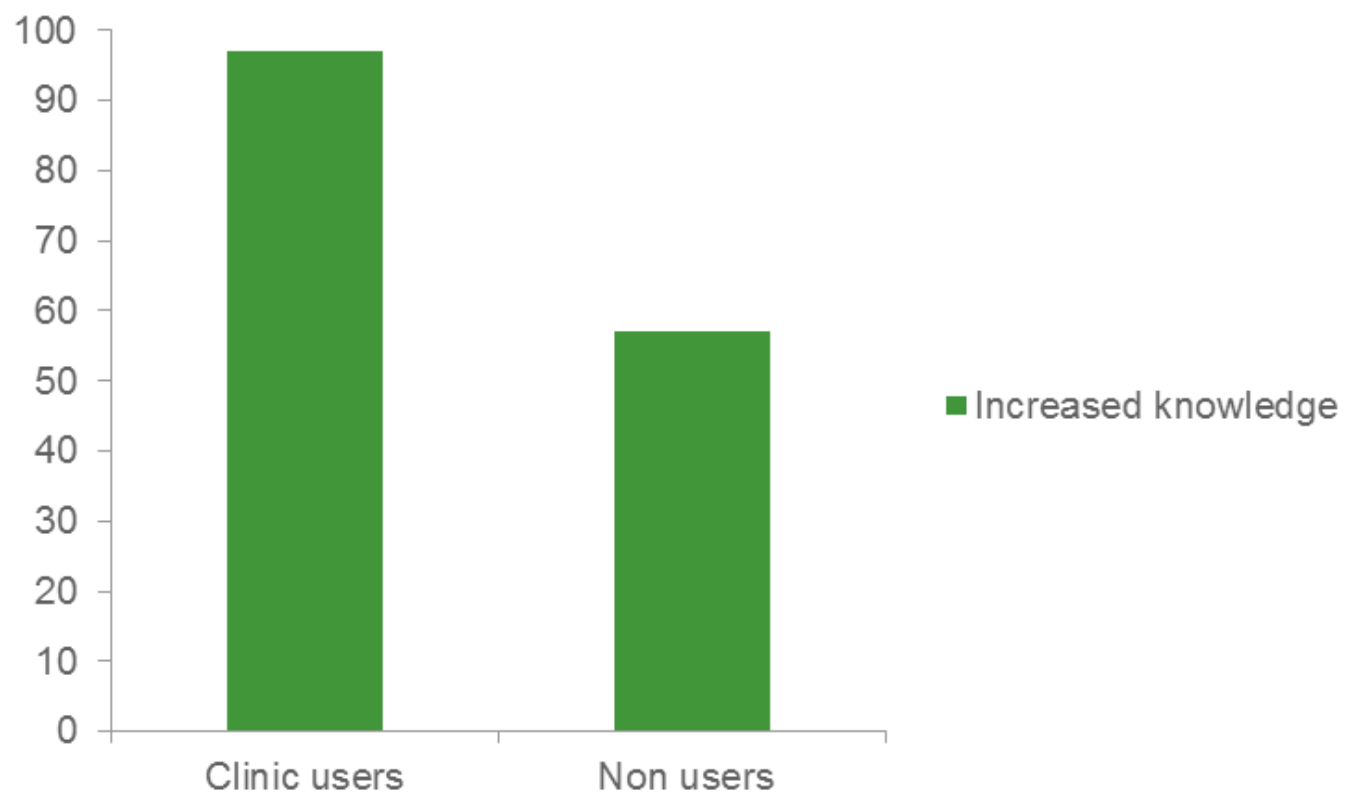

Figure 8: Percentage of farmers who indicated that they had increased their farming knowledge and practices in the preceding three years

When focusing specifically on farmers' ability to identify and address crop problems, the survey revealed that $100 \%$ of clinic users felt their ability to quickly identify crop proplems had increased, compared to only $16 \%$ of non-users (Table 3 ). The gap was similarily large for increases in farmers' abilities to communicate crop problems to others (93\% compared to $13 \%$ ) and address crop problems on their own (83\% compared to 13\%). Farmers' willingness to seek advice for crop problems was also higher for clinic users (93\%) compared to non-users (43\%). 
Table 3: Number of farmers indicating that their ability to identify and address crop problems had increased

\begin{tabular}{|l|c|c|}
\hline & $\begin{array}{l}\text { Number of clinic } \\
\text { users (30) } \\
\text { indicating an } \\
\text { increase }\end{array}$ & $\begin{array}{l}\text { Number of non- } \\
\text { users (30) } \\
\text { indicating an } \\
\text { increase }\end{array}$ \\
\hline Ability to quickly identify problems with your crop(s) & 30 & 5 \\
\hline Ability to communicate crop problems to others & 28 & 4 \\
\hline Ability to address crop problems on your own & 25 & 4 \\
\hline Quality of your farming practices & 28 & 8 \\
\hline Willingness to seek advice for your crop problems has been & 28 & 13 \\
\hline
\end{tabular}

The ability of plant clinic users to apply a range of good farm management pratices was also better than for non-users. For all of the questions regarding increased farm management skills, clinic users were on average 4.6 times more likely to indicate that their knowledge had increased (Table 4). Some of these skills included the ability to select crops, use fertilisers appropriately, monitor pests and diseases and use precautionary measures to avoid attacks, and correctly store crops. The only skill for which the ability was similar between clinic users and non-users was the ability to identify the proper time and methods for harvesting.

Of the 30 farmers who frequently attended plant clinics, 22 said that their profitability had increased as a result of visiting the clinics, with lower production costs and crop losses, and improvements in yields and market prices. Optimum pesticide use is another cost saving measure, with most farmers (24) stating that the frequency with which they used pesticide sprays had decreased. During the FGDs, some of the farmers also noted that agro-dealers were now storing the higher-quality pesticides that plant clinics were recommending.

Table 4: Farmers indicating an increase in ability to apply a range of farm management practices

\begin{tabular}{|l|c|c|}
\hline Ability to... & $\begin{array}{l}\text { Number of } \\
\text { clinic users } \\
(\mathbf{3 0}) \\
\text { indicating an } \\
\text { increase }\end{array}$ & $\begin{array}{l}\text { Number of } \\
\text { non- users } \\
\mathbf{( 3 0 )} \\
\text { indicating an } \\
\text { increase }\end{array}$ \\
\hline ...select crop & 21 & 5 \\
\hline ...prepare land & 27 & 5 \\
\hline ...use fertilisers the right way & 27 & 6 \\
\hline ...use new techniques & 27 & 8 \\
\hline ...use quality seed in the correct quantities & 29 & 9 \\
\hline ...sow on time & 27 & 4 \\
\hline ...ensure the proper time, frequency and method for ploughing & 26 & 4 \\
\hline ...ensure the proper time, frequency and method for weeding & 21 & 5 \\
\hline ...monitor pest and disease attacks, and symptoms of such attacks & 21 & 6 \\
\hline ...use precautionary measures to avoid pest and disease attacks & 23 & 6 \\
\hline ...ensure immediate actions, other than pesticides, to control pests & 17 & 6 \\
\hline ...identify the proper time and methods for harvesting & 15 & 12 \\
\hline ...correctly store crops & 22 & 2 \\
\hline
\end{tabular}




\section{The way forward}

Although the 2017 study was fairly small in scale, results indicated that the plant clinics are benefitting communities and helping them manage their crops more effectively. To increase the efficiency of data collection and improve access to Plantwise data, tablets will be rolled out to every clinic by the end of 2018. There are also plans to create an additional 30 stand-alone plant clinics in 2018, as well as 20 clinics to be linked to World Bank-funded Farmer Information Advisory Centres. All 50 clinics will be staffed by DAE extension officers.

Plant clinics are currently located in 10 of Bangladesh's 64 districts. The country's MoA are interested in mainstreaming the plant clinics into their national extension operations to cover the entire country. DAE and the Bangladesh Agricultural Research Council will be designing and implementing an independent impact study of the plant clinics to inform and shape MoA's decisions. The results of this CABI study have already been presented at a national forum and are being used to inform the design and development of the further impact study.

\section{References}

CABI. 2017. Women's access to plant clinics in Bangladesh. Plantwise report, CABI, India. 


\section{Donors}



Irish Aid

Rialtas na hÉireann Government of Ireland
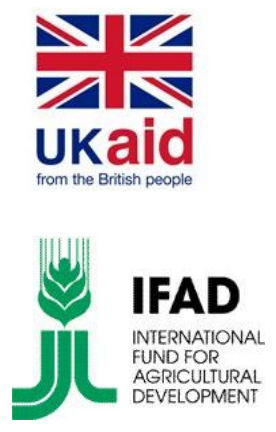

\section{Partners}
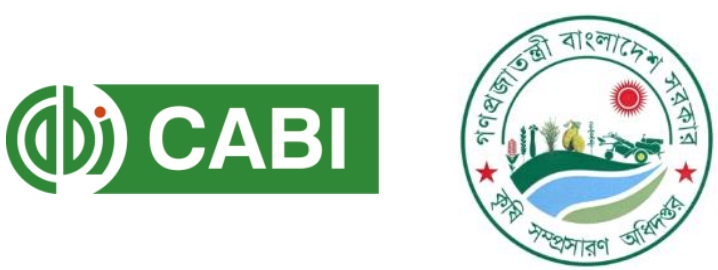

Ministry of Foreign Affairs of the Netherlands

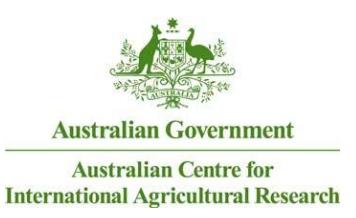

Ministry of Agriculture, People's Republic of China

\section{Authors}

Mr. Ganeshamoorthy Rajendran, CABI Country Coordinator - South Asia, Plantwise Bangladesh Mr. Rezaul Islam, Deputy Director, Plant Protection Wing, Department of Agricultural Extension (DAE)

\section{Acknowledgements}

The authors would like to thank the farmers who took the time to share their views and experiences, as well as the plant doctors and plant clinic coordinators. Others who generously supported the research study are: Mr.Md. Golam Maruf, Director General, DAE; Mr. Amitava Das, Director and Plantwise National Coordinator, Plant Protection Wing (PPW), DAE; Md. Shaikh Farid (Deputy Director), Planning, Project Implementation and ICT Wing, DAE; Mr. Hanif Sikder (Additional Deputy Director), PPW, DAE; Mr. Irshad Ali, Regional M\&E and Programme Support Officer - Asia, Plantwise; Dr. Malvika Chaudhary, Regional Coordinator, Plantwise Asia; Mr. Shah Faisal, Plantwise Data Collection Assistant, CABI; Dr. Manju Thakur, Knowledge Management Coordinator, South Asia, CABI.

The authors would also like to thank the provincial deputy directors, sub assistant plant protection officers, sub assistant agricultural officers, union agricultural officers, agricultural extension officers, and plant doctors from each district that was a part of the study.

\section{Editorial team}

Olivia Frost, WRENmedia (technical writer); Susanna Cartmell, WRENmedia (technical writer); Dannie Romney, CABI (editorial coordinator and technical writer)

To be cited as: Rajendran, G. and Islam, R. 2017. Plant clinics in Bangladesh: are farmers losing less and feeding more? CABI case study 19. DOI: https://dx.doi.org/10.1079/CABICOMM-25-8072 